\title{
Diesel engine for aircraft propulsion system
}

Stricter requirements for power in engines and difficulties in fueling gasoline engines at the airport make aircraft engine manufacturers design new engines capable of combusting fuel derived from JET-A1. New materials used in compression-ignition engines enable weight reduction, whereas the technologies of a Common Rail system, supercharging and 2-stroke working cycle enable us to increase the power generated by an engine of a given displacement. The paper discusses the parameters of about 40 types of aircraft compression ignition engines. The parameters of these engines are compared to the spark-ignition Rotax 912 and the turboprop. The paper also shows trends in developing aircraft compression-ignition engines.

Key words: diesel engine, aircraft propulsion system, power-to-weight ratio, specific fuel consumption

\section{Introduction}

The choice of the engine for light aircraft depends on several factors: power, weight, power-to-weight ratio, specific fuel consumption, power density out of which fuel consumption and engine power are fundamental. The power-to-weight ratio is important, but detailed investigations show that higher specific fuel consumption can have a greater impact on the overall aircraft design than the engine weight so engines with low specific fuel consumption which also satisfy power requirements are more often chosen [1]

The beginnings of aviation particularly preferred lightweight engines that were designed as water-cooled, in-line spark ignition engines. Optimum performance was achieved for the aircraft piston engine, always spark ignition during the Second World War. Currently, reciprocating engines are found in sports, emergency, agricultural and recreation aviation. Technically, they are mostly at a pre-war knowledge of the theory of operation, design and manufacturing technology, especially if compared to that high level of development of automotive engines. Typically, these engines are driven by carburetors of a quite primitive desing. At present, due to environmental requirements and the need to deal with climate change, it is beneficial to develop aircraft piston engines and adopt the achievements of automotive engineering such as computer-controlled Common Rail high pressure injection systems and variable pressure turbochargers.

Compression-ignition engines show several advantages. They are single-level drive units, i.e. they do not need a fuel-air mixture to be supplied, they do not need an external fuel pump and ignition source like spark plugs and magneto. The fact that there is no ignition system eliminates electromagnetic noise and reduces disturbances in aircraft navigation and radio communication. The diesel engine design is more wear-resistant due to lubricating properties of diesel fuel.

Ecological requirements and climate change make a significant opportunity to develop aircraft piston engines even by adopting the achievements in the automotive industry. Regardless of this, the introduction of diesel engines running on the unified fuel [5]. Less toxic exhaust gas results from fuel composition free from toxic substances such as lead, benzene or solvents. Their reliability and low maintenance costs result from eliminated carburetor icing, ignition system failures, and vapor jams [2].

Aircraft compression-ignition engines run on diesel and JET fuel. These fuels are also favorably low flammable and cheaper than AVGAS 100LL. Fuel, or rather its cost, plays a very important role in the life of the engine. Meanwhile, the price of diesel fuel (diesel or JET A-1) is about half the price of aviation fuel - AVGAS 100 LL [12]. The second problem is that most flights do not terminate on stations where refueling with aviation fuel is possible. This, in turn, is caused by the high expense of all required procedures to undertake a refueling - landing, refueling and scheduling for further flight, which takes up to several hours. For example, aviation fuel in Poland is available at 34 stations located in 28 cities. Diesel engine responds to customers preferences - easy access to the automotive diesel at no additional cost and the supply of aircraft engine diesel fuel.

Their primary disadvantage is their weight and troublesome low-temperature start-up and higher operating temperature range. However, fuel consumption in diesel engines is lower than in spark ignition ones, which reduces the amount of fuel to fly the same distance, enabling a larger cargo to be transported despite these engines are heavier.

The General Aviation claims that the market of ultralight aircraft is more than 3,500 units worldwide, of which Rotax provides approx. 3,000 engines for ultralight aircraft only. Maximum power of its units is near $100 \mathrm{~kW}$. Rotax provides approx. $75-80 \%$ of all aircraft engines manufactured worldwide to be dedicated to single- and double-seat aircraft. The rest is supplied by Jabiru (Australia), Continental and Lycoming (USA) and a small percentage by HKS (Japan) [14].

The light engine is also dedicated to the autogyro and ultralight aircraft. Over the last fifteen years, the autogyro has been rediscovered because as one of few aircraft it has not been subject to very strict regulations on construction and certification of new constructions as a result of little interest by uniformed services [18].

Our research focused on compression ignition engine parameters and compared them with those of aircraft spark- 
ignition and turboproped engines so the compressionignition engine to drive the lightweight airframe was defined.

\section{Overview of aircraft compression-ignition engine designs}

Many companies like AustroEngines, Continental Motors, WilkschAirmotive LTD, SMA have decided to reapply the diesel engine and are successfully investing their money to develop this technology. These engines have been produced and certified. Some aircraft diesels, including DeltaHawk, WilkschAirmotive LTD, ZocheAerodiesels and Superior remained prototypes.

The Austro Engine is owned by Diamond, an aircraft manufacturer who developed and certified the AE300, a 93 $\mathrm{kW}$ diesel engine based on the Mercedes-Benz engine to be installed on two types of aircraft. This 4-cylinder engine has a Common Rail system, 2 camshafts in the cylinder head and 16 valves. The propeller is driven with a reduction gear with torsion damper (Fig. 1).

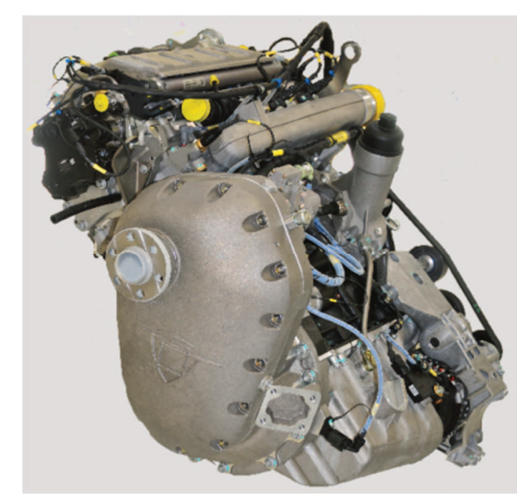

Fig. 1. Austro Engine AE 300 diesel aircraft piston engine [7]

The Safran SR305 (Fig. 2) is a 4-cylinder engine of 169 $\mathrm{kW}$ at a 3 bar inlet pressure. The boxer engine has 2 turbochargers to maintain flight parameters at an altitude of 3.8 $\mathrm{km}$, and its TBO is 2,400 hours. So its fuel consumption is by $40 \%$ lower than comparable Avgas turbocharged engines and its noise is lower by $4 \mathrm{~dB}$. Fuel consumption per one-hour flight for Cessna 182's cruise speed is 38 liters of diesel fuel compared to 51 liters of Avgas.

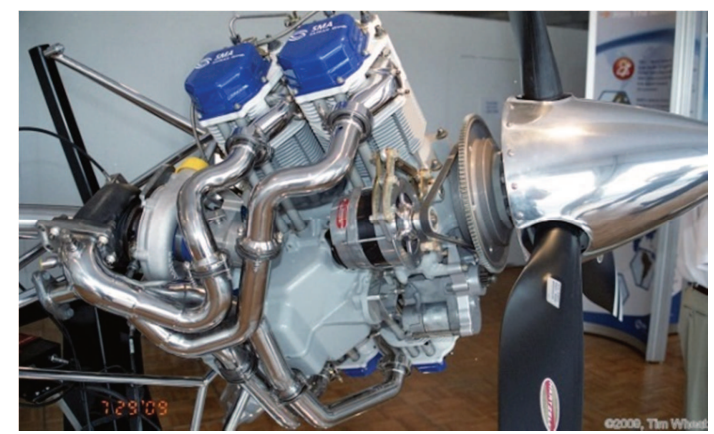

Fig. 2. Safran SR 460 diesel aircraft piston engine [16]

The engine has been certified by the EASA and the FAA. About one-third of engine cooling is provided by cylinder fins, whereas the rest by oil flowing along channels around the cylinder liner and oil coolers. The engine has no gear so power is transmitted directly to the propeller with varied stroke and a constant speed of 2,200 rpm. The French manufacturer of this engine also has on offer the SR460 which is a 6-cylinder engine of $270 \mathrm{~kW}$.

2-stroke WAM engines are 3-cylinder (WAM 165BB see Fig. 3) and 4-cylinder (WAM 167BB) engines of different maximum power. They have an indirect injection system known as IDI that unlike in structures with a direct injection system (DI) results in a slower combustion and a delayed cylinder pressure increase. So combustion occurs in a separate chamber above the piston and there is a slight loss in efficiency but a significantly smoother combustion and a lower vibration of torque.

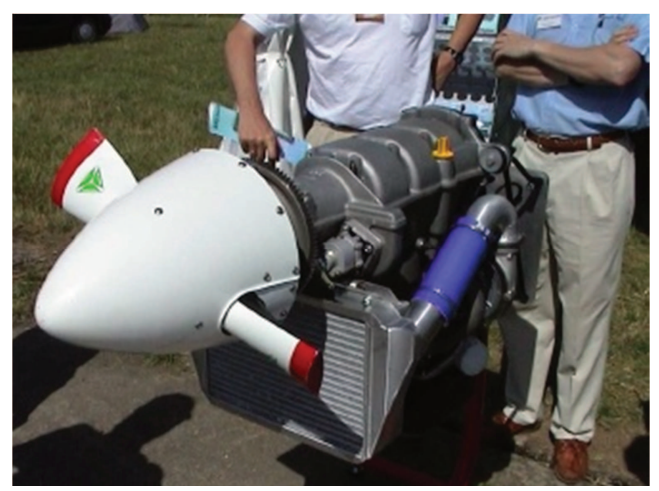

Fig. 3. WAM-165BB diesel aircraft piston engine [19]

Based on a car engine design, Subaru EE20, the boxer engine by CKT Aero Engines Ltd., England is fitted with a turbocharger, an intercooler and FADEC. It is a liquidcooled engine with an aluminum frame with steel-casting reinforced main shaft bearings. It is combined with a gearbox that drives a 3-bladed hydraulic adjustable propeller, a hub shield and its mounting. The engine has separate cooling and oil systems. The engine consumes by $40-45 \%$ less fuel, which means $50 \%$ of fuel saved compared to AVGAS engines. There is a hydraulic damping flywheel. All of its parts come from the automotive industry. The compressor is driven by multiple-V-belt.

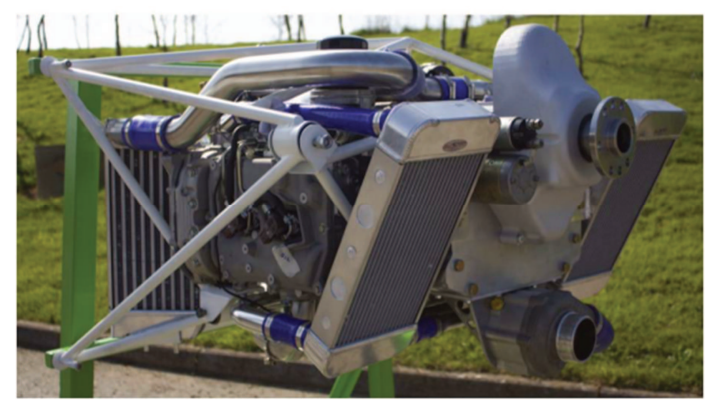

Fig. 4. CKT-240 TD diesel aircraft piston engine [8]

The Continental Motors CD series 100 (Fig. 5) is a row, 4-cylinder, turbocharged engine of $99 \mathrm{~kW}$ and $114 \mathrm{~kW}$. The engine is a Mercedes-Benz A-class-sourced item. It is liquid-cooled with a Common Rail system.

The Superior Gemini 100 is a 2-stroke, liquid-cooled diesel engine with 3 cylinders and 6 opposed pistons. Each cylinder is fitted with a Common Rail injector and a glow 
plug. Its steel liners are inside a die cast aluminum block. The opposite piston engine is driven by 6 pistons and 2 crankshafts mounted at the sides of the engine. The crankshafts are made of high quality steel EN4O used primarily at Formula One. Inside, there is a gearbox to reduce speed $(4,000 \mathrm{rpm})$ transmitted to a propeller $(2,500 \mathrm{rpm})$. There is a dry sump lubrication system. Figure 6 shows the cover of sliding cylinder liners with its intake and exhaust systems. A compressed air fuel mixture goes through small holes on the left side of the liner, and the outlet is on the right side (larger holes).

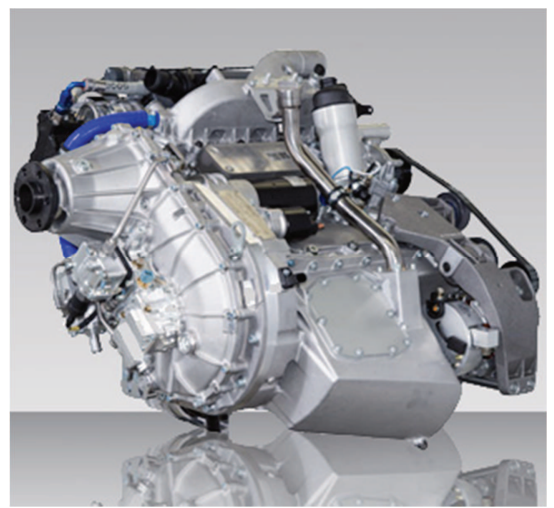

Fig. 5. CD-135/155 diesel aircraft piston engine [9]

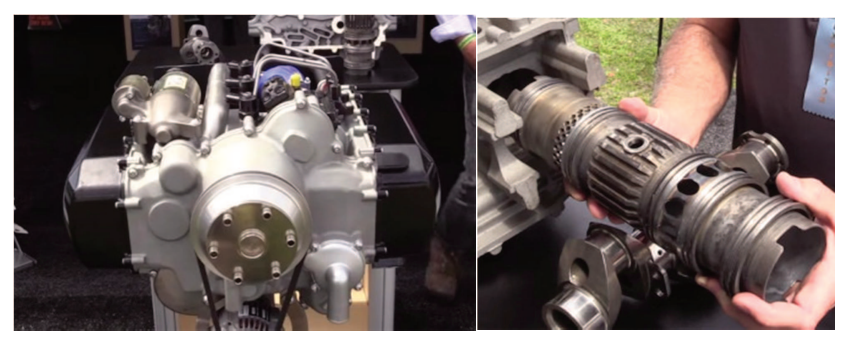

Fig. 6. Gemini 100 diesel aircraft opposite piston engine (right) and its cylinder liner (left) [6]

The DAIR-100 (Fig. 7) is a $75 \mathrm{~kW}, 2$-stroke opposedpiston OPOS engine design with 4 pistons, 2 cylinders and 2 crankshafts coupled with a gearbox to drive a propeller. Its design is similar to that of the Gemini. Its cylinder intakes and outlets are rings opened by moving pistons. This is a liquid cooled engine powered by a high pressure fuel pump. In each cylinder there are two fuel injectors. The engine is supercharged with a centrifugal compressor.

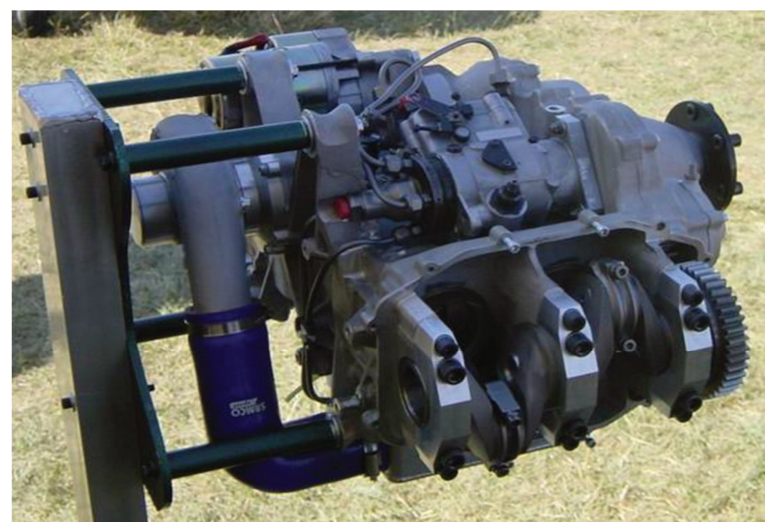

Fig. 7. DAIR 100 diesel aircraft piston engine [10]
The Weslake A80 (Fig. 8), a 2-stroke opposed-piston engine has a special large-diameter flywheel in front of the engine. It is just where a propeller, an alternator drive and a compressor are installed. This 2-stroke engine with 2 cylinders reaches $60 \mathrm{~kW}$ at a speed of 4,800 rpm. The liquidcooled engine is powered by an in-line fuel pump.

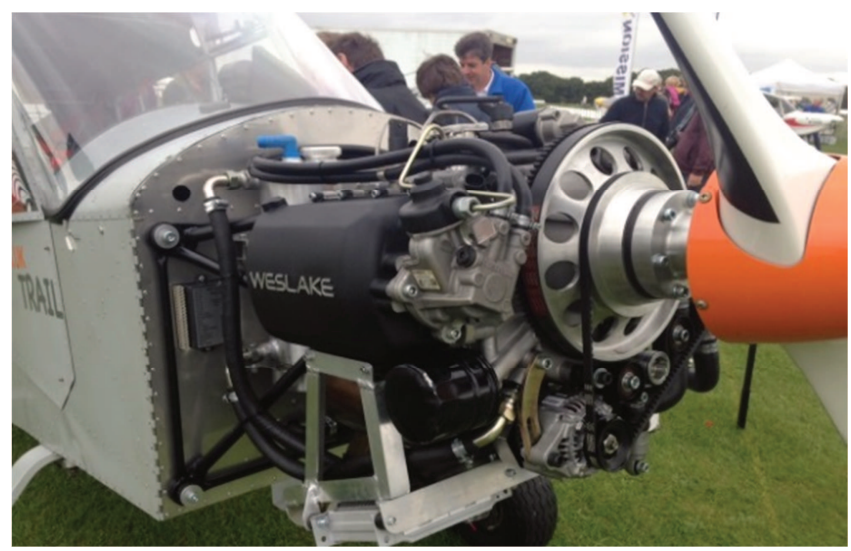

Fig. 8. Weslake A80 diesel aircraft opposite piston engine [17]

The DeltaHawk DH series (Fig. 9) is a 2-stroke V4 engine. Its cylinders are supplied with 4 separate unit injectors (137 MPa) and a supply pump (0.6 MPa). Its supply system is completely mechanical. Its charge system consists of a vbelt-driven compressor from a shaft, a supercharger with a by-pass valve and an intercooler. Its mechanical compressor provides for $50 \%$ of power and is used at a start-up and in emergency. In other states, its compressor does not work. There are inlet widows instead of valves. This engine with a dry sump is pressure-lubricated.

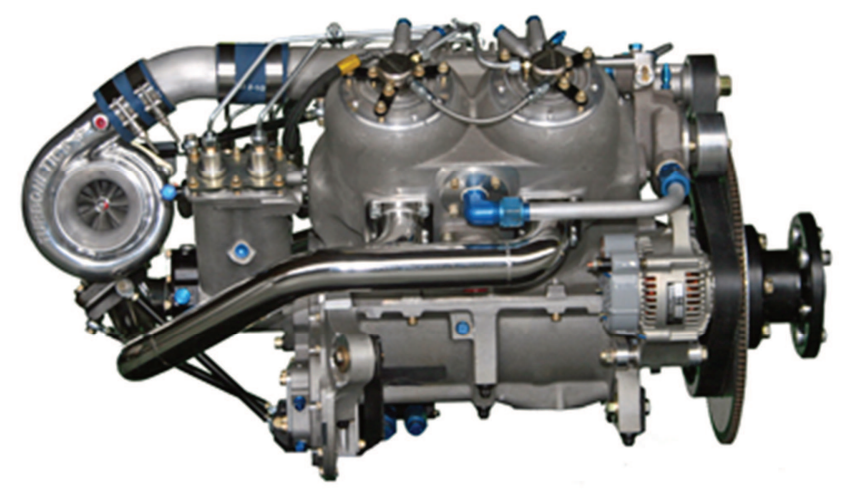

Fig. 9. Delta Hawk diesel aircraft piston engine [11]

Zoche aero-diesels, a German manufacturer, constructed three modular engines of different configurations of cylinders and power (Fig. 10). Its air-cooled 2-stroke engine directly drives a propeller. It is based on a direct fuel injection system. It uses a 2-stage supercharging system, i.e. a turbine and a supercharger as well as an intercooler to provide an intake air absolute pressure of 3 bars. A quad scroll compressor is installed inside an intercoller body. Low noise is achieved by a 2-stroke cycle and supercharging. There is dry sump pressure lubrication. The alternator is directly driven. There is no starter (a start-up by compressed air) and rubber parts. 


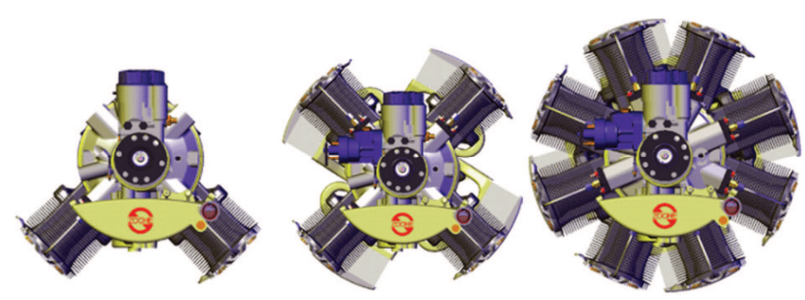

Fig. 10. Zoche aero-diesel ZO series diesel aircraft piston engines [20]

\section{Aircraft diesel engine basic parameters}

There have been created a database of about 40 diesel piston engines installed in light airframes and gyroplanes. The database provides basic parameters of available engines. Piston compression-ignition engines are in the former part, whereas opposed-piston compression-ignition ones in the latter one. For example, the parameters of the most popular engines like the Rotax and the turboshaft engine are investigated. There are compared the power, weight and brake specific fuel consumption (BSFC) of the 180-Watt turboshaft PBS TP-100 and gasoline, piston Rotax engines. In the turboshaft engine, the pilot controls power with a variable blade angle propeller. Its planetary gearing reduces turbine shaft speed at an outlet shaft from $61,000 \mathrm{rpm}$ to $2,750 \mathrm{rpm}$. The engine weighs $62 \mathrm{~kg}$ and have fuel consumption equal to $525 \mathrm{~g} / \mathrm{kWh}$.

The air and liquid cooled (heads) Rotax 912-ULS has a power of $75 \mathrm{~kW}$ at $5,800 \mathrm{rpm}$ and weighs $55 \mathrm{~kg}$. Its fuel consumption is equal to $285 \mathrm{~g} / \mathrm{kWh}$. The engine is 4cylinder boxer engine that operates in a 4 -stroke cycle. The engine has a turbocharger and an electric valve. There is a dry sump lubrication system with an extra oil tank.
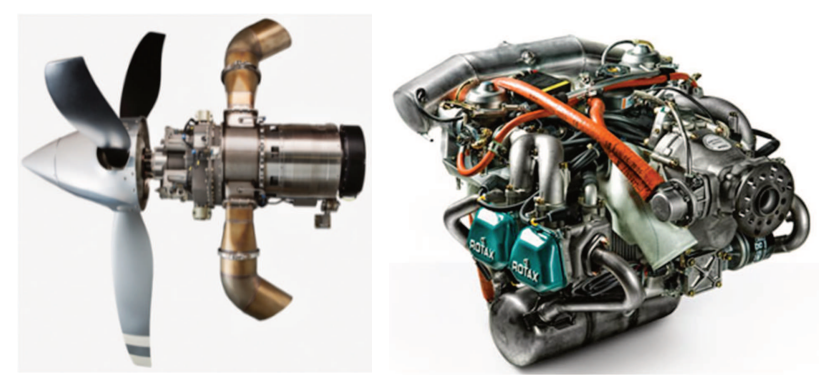

Fig. 11. Aircraft turboshaft TP- 100 engine (right) [15] and Rotax 912ULS spark ignition engine (left) [13]

Some compression-ignition engines are based on car engines so the following technical parameters are examined: cylinder arrangement, engine power, weight, fuel consumption, etc. Our examination enabled us to define the configuration of the aircraft compression-ignition engine. The examined parameters included the main dimensions of the engine (stroke, bore), cylinder configuration, a crankshaft speed range and basic operating parameters. There were described the tendencies of the average value of a given parameter.

\subsection{Operating cycle}

Diesel engines are heavier than gasoline ones due to the nature of their operating cycle, i.e. much higher compression pressures, higher combustion pressures and larger gas forces. If these forces increase, the engine construction needs to be strengthened and more rigid so an engine block, crank-piston systems and a crankshaft are heavier. Their larger weight can be compensated for their more powerful charging systems.

The 2-stroke cycle allows for a significantly better power-to-weight ratio than it is in the 4-stroke cycle. The 2stroke engine design is mechanically simpler so more reliable due to fewer moving parts. camshafts, valves, timing gear system were replaced by a port timing with inlet windows to be opened with a reciprocating piston. Engine weight is also reduced as there is no valve system. A regular operation and a very low vibration of a 2 -stroke engine results from its single stroke in the cylinder per rotation.

It is important to note that 2-stroke engines due to their double firing frequency versus 4-stroke engines, have 30$40 \%$ reduced cylinder pressure and gas temperature than the 4-stroke engine at the same power rating [3]. This translates to the 2-stroke engine having approximately $30 \%$ lower $\mathrm{NO}_{\mathrm{x}}$ emissions than the 4-stroke engine.

The 2-stroke cycle is, however, less efficient because the air-fuel mixture is diluted by exhaust gas and partially released through the exhaust window. Some difficulties occur when the 2-stroke engine is lubricated and cooled [6].

More than $30 \%$ of the modern aircraft diesel engines are 2-stroke. All opposed-piston designs are 2-stroke, whereas the rest are 4-stroke car engines.

\subsection{Cylinder arrangement}

Cylinder arrangement in aircraft engines enables us to minimize engine weight and a front surface area behind a propeller. Different types of cylinder arrangement are abbreviated as follows: B (boxer), R (in-line), G (radial), V (V-type), the V90 (V-type engine with cylinders at an angle of $90^{\circ}$ ), V180 (V-type engine with cylinders at an angle of $180^{\circ}$ ), OPE (opposite-piston engine). A dominant configuration is flat cylinder arrangement, i.e. boxer (10 engines) and opposed-piston arrangement (7 engines).

OPE engines have two opposed cylinders per one module of the crankshaft between them and two pistons oppositely reciprocating per each cylinder. Accordingly, the cylinder head and valves can be removed so such an engine design is much more efficient and simpler, with much less parts than in the other engines.

This type of engines is lighter because its cylinders/pistons are opposite each other so they are able to balance inertia forces and no extra balancing masses are necessary to improve rotational speed uniformity.

Our examination of aircraft engine designs shows that aircraft compression-ignition engines based on car engine designs are in-line ( 8 engines) and $\mathrm{V} 90^{\circ}$ ( 7 engines). This is the most compact type of design capable of achieving the lowest weight-to-power ratio. In addition, the V-type design is compact and easy to be installed in gyrocopters and helicopters. The crankshaft with $90^{\circ}$ cranks enables us to minimize fluctuations of instantaneous torque.

The in-line engine design makes the engine heavier because of its long and heavy crankshaft. However, if applied in airframes, it has the smallest frontal surface.

The radial engine has the most lightweight crank system and the largest frontal surface. The two engines here have such a cylinder arrangement only. 


\subsection{Number and displacement of cylinders}

Figure 3.1 summarizes the number of cylinders in each type of aircraft compression-ignition engines. The red frame indicates opposed-piston engines. Our research indicates that the engines have on average 4 cylinders and opposed-piston engines on average 3 cylinders (6 pistons). High power Vtype and radial engines have 6 or 8 cylinders.

The opposed-piston ( 3 cylinders and 6 pistons) engine is a well-balanced engine, which is its advantage. Charge exchange there is optimal due to its dynamics, i.e. charge exchange is undisturbed so there is a continuous stream of exhaust gas mass that drives a turbine and compressorbased air supercharge is efficient. The 2-cylinder (4 pistons) engine design shows, however, long breaks in charge exchange resulting in turbocharger power loss, particularly at low load and speed. Therefore, a mechanical compressor is necessary but engine performance is reduced [4].

An average displacement of a single cylinder reaches $290 \mathrm{~cm}^{3}, 660 \mathrm{~cm}^{3}$ and $690 \mathrm{~cm}^{3}$ in gasoline, OPE and other aircraft diesel engines, respectively. It should be pointed out that a displacement of a single cylinder in the OPE engine results from a movement of two pistons (stroke of 2 pistons). Therefore, a displacement of a half of a single cylinder produced by a movement of a single piston is 330 $\mathrm{cm}^{3}$. A displacement of supercharged engines is less than an average level.

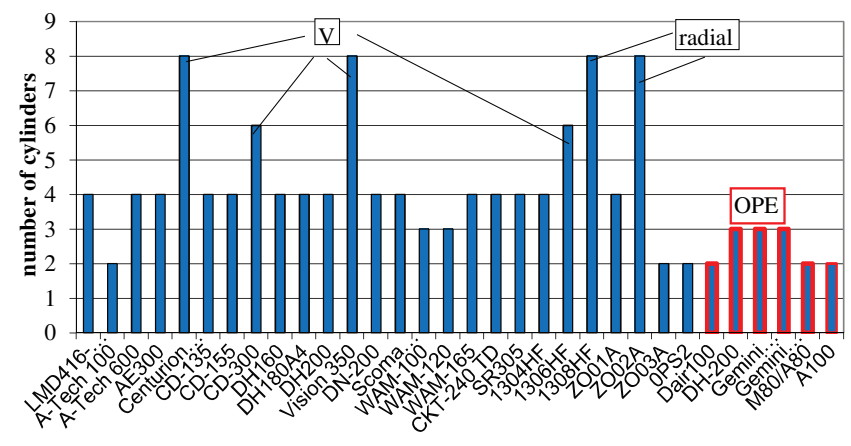

Fig. 12. Cylinder arrangement in diesel aircraft engines.

\subsection{Engine power and weight}

Figure 13 summarizes the specific engine output (power/unit displacement ratio) of individual aircraft engines This parameter describes the efficiency of an engine in terms of the brake horsepower it outputs relative to its displacement. and is around $50 \mathrm{~kW} / \mathrm{dm}^{3}$. One liter of displacement generates $66 \mathrm{~kW}$ in gasoline engines, $52 \mathrm{~kW}$ in OPR engines and $64 \mathrm{~kW} / \mathrm{dm}^{3}$ in the other diesel engines.

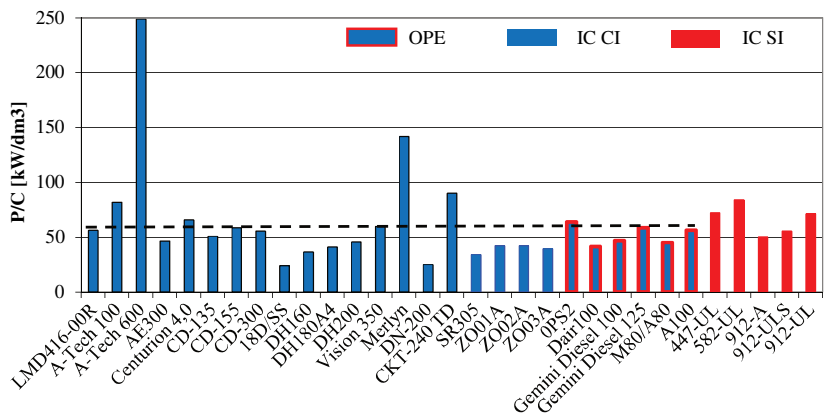

Fig. 13. Power/unit displacement ratio for aircraft piston engines
Figure 14 summarizes power-to weight ratio $\mathrm{P} / \mathrm{W}$ (specific power), so the correlation between power density and weight for models of each aircraft engine. This parameter is very important for aircraft engines and should be as high as possible approaching $1 \mathrm{~kW} / \mathrm{kg}$ as indicated by the dotted line. All gasoline Rotax engines and turboshaft engines achieve higher values. Modern classic diesel engines are not able to achieve such a good value of P/W. Our research shows that currently manufactured OPE engines can achieve a good value of this parameter near $1 \mathrm{~kW} / \mathrm{kg}$, and the best values are reached by the radial Zoche Aerodiesels ZO02A $(1,8 \mathrm{~kW} / \mathrm{kg})$. A most of engines has power below $200 \mathrm{~kW}$. The engines marked above the dotted line are high power lightweight engines. Their power density, $\mathrm{P} / \mathrm{M}$, is more than $1 \mathrm{~kW} / \mathrm{kg}$. This group of engines includes gasoline Rotax engines, turboshaft engines and most OPE engines.

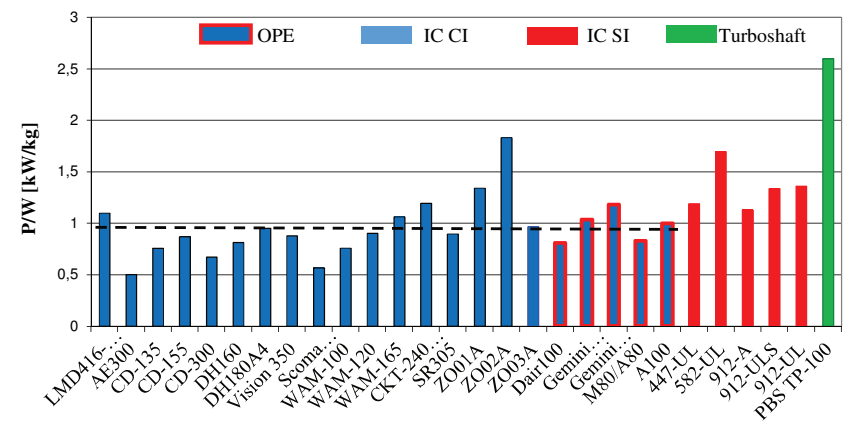

Fig. 14. Power-to-weight ratio for aircraft engines

Most of the engine designs studied here is liquid-cooled so their total weight is significantly higher but a defined level of engine temperature is better maintained and noise emission is lower than in air-cooled engines, which is their strong point. Moreover, the maximum efficiency can be achieved while monitoring coolant temperature depending on load. The group of air-cooled engines includes gasoline engines, the SMA, the VM Italy, the Zoche Aerodiesel and the Achates Power.

Aircraft engine power can substantially improve the use of a supercharging system. Typically, the lightweight turbine is used to achieve a defined level of power or to normalize the engine (to maintain the sea level pressure level regardless of the altitude). Engines capable of operating at an altitude above $2,000 \mathrm{~m}$ need a supercharging system as a mechanical compressor, pressure wave supercharging (dynamic charging) or a turbocharger. The last solution applied in engines based on car engine designs is most popular. Their power output is proportional to the mass of air that fills cylinders. The application of a mechanical compressor is most frequent in all of the analyzed OPE engines, and some of them are fitted with a turbocharger.

\subsection{Fuel consumption}

Here we summarizes Economy Cruise break specific fuel consumption (BSFC) in $\mathrm{g} / \mathrm{kWh}$ for each of the aircraft engines. This value can be achieved for the 0.65 to 0.75 nominal power flight. Figures 15 and 16 depict power and weight as a function of the BSFC of the diesel engine designs studied here. The compression-ignition engines stud- 
ied here have their Economy Cruise BSFC close to 200 $\mathrm{g} / \mathrm{kWh}$. Our research shows that the ZO03A Zoche and the Rotax 912 are the best designs in terms of their BSFC and power-to-weight ratio.

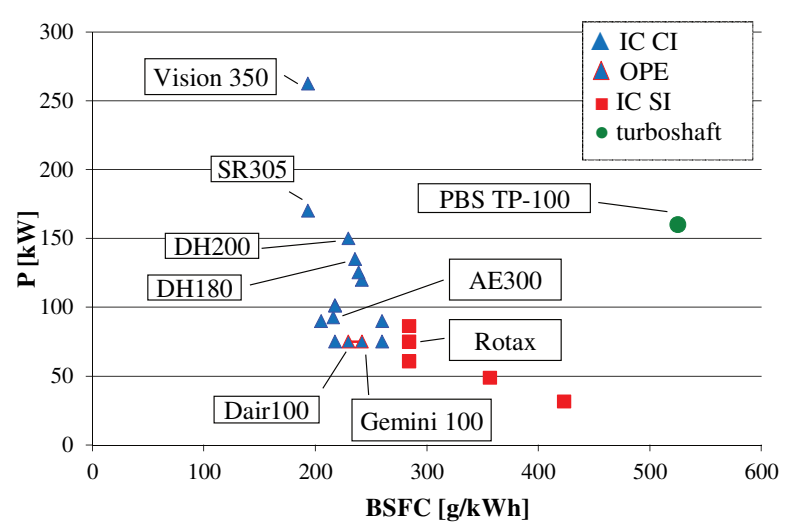

Fig. 15. Power vs. BSFC for the aircraft engines studied here

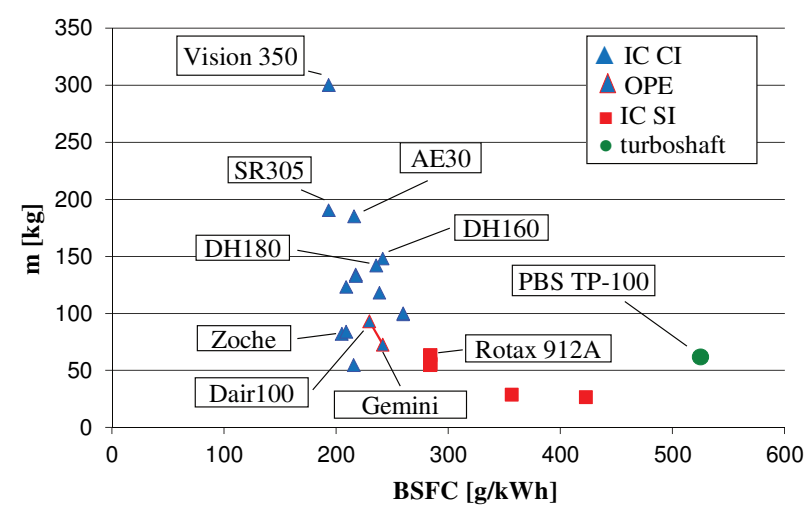

Fig. 16. Weight vs. BSFC for the aircraft engines studied here

\subsection{Chamber dimensions}

The engine chamber is defined by the stroke $S$ and the bore $\mathrm{D}$ (diameter of cylinder liner). The chamber in a typical engine is limited by the head, the moving piston crown and cylinder liner walls. The chamber of OPE engine is shaped by two moving pistons and cylinder liner walls. The stroke-to-bore ratio, indicated as $\mathrm{S} / \mathrm{D}$, specifies engine main dimensions. Figure 17 summarizes the values of S/D for the aircraft engines studied here. S/D for today's compressionignition engines ranges from 0.9 to 1.1 , whereas that for gasoline aircraft ones is less than 0.8. Achates with AVL examined in detail S/D while designing a 2-stroke opposedpiston engine and concluded as follows [3]:

- the in-chamber heat exchange reduces with increasing the $S / D$ ratio because the chamber area/volume ratio is reduced. Such reduced heat exchange directly improves engine thermal efficiency and reduces heat transfer to a cooling medium.

- an engine flush is more efficient if the S/D ratio increases, and pumping increases below 1.1 of the S/D ratio.

- friction in the engine is non-linearly correlated to the $\mathrm{S} / \mathrm{D}$ ratio so friction increases when the $\mathrm{S} / \mathrm{D}$ ratio reaches 1.15 although it is much less than heat transfer and pumping.
Compression ratio $\varepsilon$ for compression-ignition engines ranges between 12 and 21 . Figure 18 summarizes the theoretical compression ratio for the models of the aircraft engines. Compression ratio for gasoline engines ranges from 7 to 8.5 , for diesel engines its average value is 18 .

Heat generated by increased pressure is high enough to ignite the fuel in the chamber. Increased compression ratio results in higher power because of pressure and temperature at the end of the compression stroke. Too high compression $\varepsilon$, however, has an adverse impact on load of the crankpiston system so geometric compression ratio $\varepsilon$ should not be more than 22 due to thermal and mechanical loads that have an impact on lifetime. Too low compression ratio, on the other hand, has an adverse impact on performance and fuel consumption.

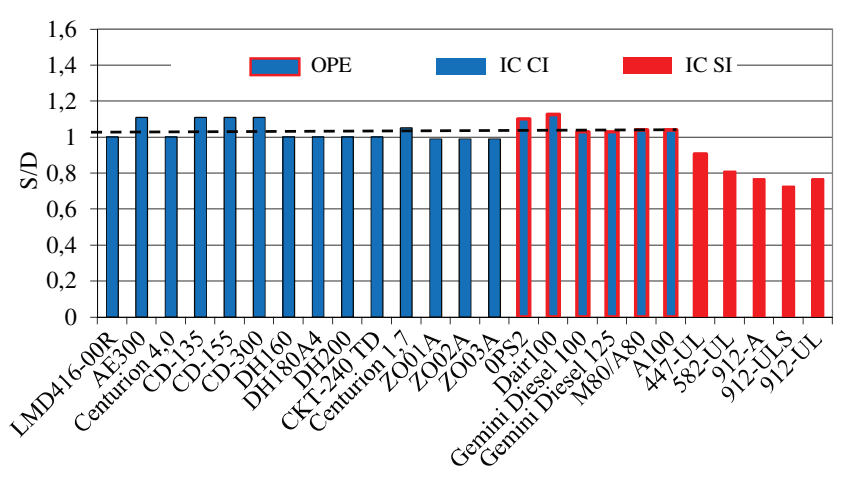

Fig. 17. Stroke vs. bore as S/D ratio for the aircraft piston engines studied here

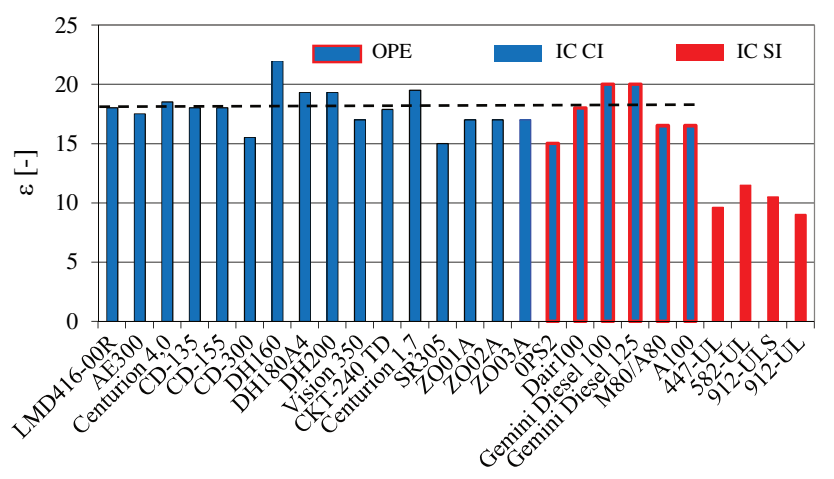

Fig. 18. Compression ratio for the models of the aircraft piston engines studied here

\section{Summary}

The development tendencies for aircraft compressionignition engine are twofold, i.e. modifying car engine designs and designing completely new engines, generally 2stroke opposed-piston engines. Our investigation of available aircraft compression-ignition engines shows that they are chiefly 4-stroke, 4-piston, liquid-cooled, and supercharged. The average displacement for analyzed diesel aircraft engines is $3,640 \mathrm{~cm}^{3}$, whereas for the Rotax 912UL it is $1,211 \mathrm{~cm}^{3}$. The average displacement per cylinder is $812 \mathrm{~cm}^{3}$, and for the Rotax 912-UL reaches $303 \mathrm{~cm}^{3}$. The disadvantage of diesel engines is power-to-weight-ratio, which has average value equal to $0.97 \mathrm{~kW} / \mathrm{kg}$, while for the Rotax 912-UL is about $1.34 \mathrm{~kW} / \mathrm{kg}$. If these values are compared with the values of other engines, diesel engines 
clearly stand out from their competition. But our comparative investigation shows that diesel engines consume much less fuel than spark-ignition engines and turboprops. The average fuel consumption amounts to $237 \mathrm{~g} / \mathrm{kWh}$ and to $332 \mathrm{~g} / \mathrm{kWh}$ and $548 \mathrm{~g} / \mathrm{kWh}$ for the spark ignition Rotax 912-UL and turboshaft PBS TP100 respectively.

The average rotational speed for diesel engines is 2,827 rpm and for the Rotax 912-UL - 5,800 rpm. So diesel engines can run without reduction gear and the same decrease mass of the whole aircraft power plant.

Power, size, and better use of displacement are now the greatest challenges faced by today's engine designers to design compression-ignition engines capable of holding a dominant position in the aviation market. Diesel engines in the aviation industry are quite new compared to spark ignition engines but they have already managed to outrun much competing engines in reduced fuel consumption and toxic emissions. Accordingly, in the forthcoming years, investors are inspected to be more interested in these designs which can crowd out spark-ignition engines.

\section{Acknowledgement}

This work has been realized in the cooperation with The Construction Office of WSK "PZL-KALISZ" S.A." and is part of Grant Agreement No. POIR.01.02.00-00-0002/15 financed by the Polish National Centre for Research and Development.

\section{Nomenclature}

TBO time between overhaul

FAA Federal Aviation Administration

EASA European Aviation Safety Agency

IDI indirect injection

BSFC brake specific fuel consumption

OPE opposite piston engine

RPM revolutions per minute
ICE internal combustion engine

CI compression ignition

SI spark ignition

$\mathrm{P} / \mathrm{C}$ power-to-displacement ratio

$\mathrm{P} / \mathrm{W}$ power-to-weight ratio

$\varepsilon \quad$ compression ratio

\section{Bibliography}

[1] DONOVAN, R. The design of an uninhabited air vehicle for remote sensing in the cryosphere. University of Kansas 2007.

[2] FAROKHI, S. Aircraft propulsion. ISBN: 978-1-118-806777, 2004.

[3] FLINT, M., PIRAULT, J.P. Opposed piston engines: evolution, use, and future applications. SAE International. PA ISBN 978-0-7680-1800-4, Warrendale 2009.

[4] REGNER, G., JOHNSON, D., KOSZEWNIK, J., DION, E. et al. Modernizing the opposed piston, two stroke engine for clean, efficient transportation. SAE Technical Paper. 2013, 2013-26-0114.

[5] Revised IPCC Guidelines for National Greenhouse Gas Inventories, 1996.

[6] www.achatespower.com

Michał Gęca, DEng. - Faculty of Mechanical Engineering at the Lublin University of Technology.

e-mail:M.Geca@pollub.pl

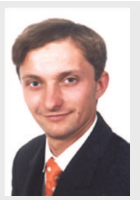

Mariusz Sułek, Eng. - Faculty of Mechanical Engineering at the Lublin University of Technology.

e-mail:M.Sulek@pollub.pl
[7] www.austroengine.at

[8] www.cktaeroengines.com/

[9] www.continentalmotors.aero

[10] www.dair.co.uk

[11] www.deltahawkengines.com

[12] www.dlapilota.pl/wiadomosci/dlapilota/aktualizacja-cenypaliw-lotniczych-na-polskich-lotniskach

[13] www.faston.pl

[14] www.generalaviationnews.com/2015/01/01/measuringgrowth-in-lsa/

[15] www.pbsvb.com

[16] www.smaengines.com

[17] www.weslake.eu

[18] www.wiatrakowce.org

[19] www.wilksch.net

[20] www.zoche.de

Zbigniew Czyż, MEng. - Faculty of Mechanical Engineering at the Lublin University of Technology.

e-mail: Z.Czyz@pollub.pl 